\title{
POR UMA EDUCAÇÃO FEMINISTA NA AMAZÔNIA: DIÁLOGOS ENTRE PAULO FREIRE E BELL HOOKS
}

\section{TOWARDS A FEMINIST EDUCATION IN AMAZONIA: DIALOGUES BETWEEN PAULO FREIRE AND BELL HOOKS}

\author{
Adriana Dias de Moura ${ }^{1}$ \\ Universidade Federal do Pará - UFPA \\ Isabell Theresa Tavares Neri2 \\ Universidade Estadual do Pará - UEPA \\ Vera Lúcia de Cristo Lobato 3 \\ Universidade Estadual do Pará - UEPA
}

\begin{abstract}
Resumo
O objetivo deste artigo é dialogar sobre práticas educativas que atentem para a trama de opressões vivenciadas pelas mulheres no território amazônico, tendo por base o pensamento da ativista norte-americana Bell Hooks e do pedagogo brasileiro Paulo Freire. No encontro entre os pensamentos desses dois intelectuais, busca-se identificar os pontos de convergência de seus escritos na direção de uma pedagogia feminista, comprometida com a criticidade, a dialogicidade e a amorosidade no seio de um processo pedagógico voltado para mulheres da região Amazônica. Trata-se de uma pesquisa bibliográfica. Entre os resultados destaca-se que Bell Hooks e Paulo Freire partilham seus conhecimentos e experiências com os oprimidos e costuram uma pedagogia com um sentido de justiça. Pedagogia que possibilita a crítica e a indignação perante as violências e desumanizações que mulheres sofrem no contexto social na Amazônia.
\end{abstract}

Palavras-Chave: Educação feminista; Paulo Freire; Bell Hooks; Amazônia.

\section{Abstract}

The objective of this article is to discuss educational practices that attempt to deal with the oppression experienced by women in the Amazonian territory, based on the thinking of the American activist Bell Hooks and the Brazilian pedagogue Paulo Freire. In the encounter between

\footnotetext{
1 Doutoranda em Educação (Educação, Cultura e Sociedade). Orientanda da Profa. Dra. Lúcia Isabel da Conceição Silva. Mestra em Educação(UFPA). Especialista em Gestão Escolar (UNAMA). Graduada em Pedagogia (UFPA).

2 Mestranda em Educação, orientada pela Prof. Ivanilde Apoluceno de Oliveira e licenciada em Pedagogia pela Universidade do Estado do Pará - UEPA. Educadora e pesquisadora do NEP.

${ }^{3}$ Mestranda em Educação-PPGED/UEPA (2017), orientanda da Prof. Dr. ${ }^{a}$ Ivanilde Oliveira. Especialista em História Afro-brasileira e Indígena-UFPA/CUNTINS. Graduada em História pela mesma instituição.
} 
the thoughts of these two intellectuals, it is sought to identify the points of convergence of their writings in the direction of a feminist pedagogy, committed to criticism, dialogue and amorousness within a pedagogical process directed at women in the Amazon region. This is a bibliographical research. Among the results is that Bell Hooks and Paulo Freire share their knowledge and experiences with the oppressed and sew a pedagogy with a sense of justice. Pedagogy that allows criticism and indignation at the violence and dehumanization that women suffer in the social context in Amazonia.

Keywords: Feminist education; Paulo Freire; Bell Hooks; Amazonian Region.

\section{INTRODUÇÃO}

Pensar uma educação para mulheres ribeirinhas na Amazônia paraense requer uma reflexão crítica sobre a realidade das mulheres que vivem nas florestas, nos campos e nas águas. O entrelaçamento das singularidades e pluralidades imersas em suas pedagogias cotidianas perpassam, na ótica de Wolff (1999), pelas lutas travadas no seio familiar, no âmbito social e no contexto político.

Essas mulheres aprendem a sobreviver por meio de seus conhecimentos populares em meio a uma esfera social que insiste em silenciar as suas vozes. Há uma constelação de opressões:

A saúde dessas mulheres está diretamente relacionada às condições de vida e de trabalho, que têm produzido riscos, adoecimentos e agravos à sua saúde seja pela contaminação por agrotóxicos e outros agentes químicos, seja pela frequente exposição ao sol sem proteção, assim como os acidentes de trabalho, suas longas jornadas de trabalho, seja no campo, no extrativismo, na pesca, na mariscagem, como no ambiente doméstico, configurando a duplaltripla jornada (BRASIL, 2015, p.8).

Destaca-se, nesse contexto, os casos de escalpelamento que ocorrem em muitos transportes fluviais na Amazônia e acometem, principalmente, as mulheres e crianças ribeirinhas. Embarcações que em sua maioria não possuem a carenagem responsável por cobrir o motor dos barcos. Nesse sentido, o escalpelamento ocorre quando os cabelos engatam na máquina e são arrancados e, na maior parte dos casos, arrancam o couro cabeludo, bem como, chegam a lesionar orelhas, olhos e outras partes do corpo (ALMEIDA, 2016).

Góes (2009, p.118) chama a atenção para os desafios enfrentados pelas mulheres após o acidente. Ao descrever a situação vivenciada por uma moça escalpelada a autora enfatiza que "o acidente não castrou a sua identidade de mãe, esposa, mulher, mas a tornou uma mulher sem saúde, sem beleza e sem liberdade."

Nesse contexto, percebemos a necessidade de se pensar as representações sobre o que é ser mulher, corpo feminino e relações de gênero, de raça e de classe enquanto 
construções sociais e históricas. Portanto, corrobora-se com o pensamento de que "é através das instituições, da cultura, das crenças, das leis civis, da educação, da divisão sexual do trabalho, que se constroem homens e mulheres que, a partir de valores desiguais, envolvem-se em uma relação de dominação" (BRASIL, 2015, p.8). Sobretudo, uma educação que problematize situações emergenciais como as violências domésticas, sexuais e institucionais, a divisão sexual do trabalho e a negação de direitos vivenciados por essas mulheres no território amazônico.

Com o objetivo de dialogar sobre práticas educativas que atentem para a trama de opressões vivenciadas pelas mulheres no território amazônico, este artigo procura, em um primeiro momento, tecer uma trajetória histórica sobre a educação na Amazônia de maneira a mapear os avanços e entraves que perscrutam essa caminhada. Posteriormente, tece-se um perfil da ativista norte-americana Bell Hooks e do pedagogo brasileiro Paulo Freire, de maneira a conhecermos as suas instigantes experiências de vida que, de uma certa forma, alicerçam as suas epistemologias. Em seguida, realiza-se um encontro entre os pensamentos desses dois intelectuais. De maneira a identificarmos os pontos de convergência de seus escritos na direção de uma pedagogia feminista, permeada pelo Eros e pelo erótico, na perspectiva da higiologia e, por isso, comprometida com a criticidade, a dialogicidade e a amorosidade no seio de um processo pedagógico voltado para mulheres de regiões subalternas.

\section{EDUCAÇÃO NA AMAZÔNIA: POSSIBLIDADES E ENTRAVES}

Loureiro (2007) se propõe a realizar uma breve trajetória histórica percorrida pela educação, na Amazônia, a partir da década de 1940. Nesse recorte histórico, chama a atenção a quantidade expressiva de mulheres que compunham a população amazônica, girando em torno de $41 \%$.

Mulheres que na visão da geógrafa, em sua maioria, se ocupavam ou de tarefas domésticas não remuneradas, ou de atividades exercidas no âmbito das poucas e modestas escolas existentes. Além das atividades polivalentes, marcadas pela caça, pela pesca e pela agricultura.

Em um cenário notabilizado por uma vida modesta e de poucas oportunidades profissionais, o sonho de uma boa parte das moças era o de se tornarem professoras:

Embora a educação fosse considerada como um valor intelectual relevante para a formação das pessoas, esse valor tornava-se realmente essencial, quando alguém pretendia dedicar-se a uma profissão específica que exigia uma formação em nível superior. Ou para exercer o magistério primário, 
que requeria o antigo Curso Normal, procurado pela maior parte das mulheres que ingressavam numa vida profissional (LOUREIRO, 2007, p.3).

A pesquisadora explica que em uma Amazônia, em plena década de 1940, onde o extrativismo imperava, atividades realizadas em garimpos, em florestas e nos rios não exigiam um alto nível de escolarização às mulheres e aos homens que estavam envolvidos (as) nas mesmas.

Nesse sentido, "uma professora dedicava-se à tarefa de desemburrar os alunos ensinados em algumas cartilhas" (LOUREIRO, 2007, p.18). Processos pedagógicos que se limitavam às 4 operações básicas de matemática, bem como noções de leitura e de escrita.

Nesse ensejo, em um retrato amazônico dominado pela flora e pela fauna, o processo de escolarização parecia distante das reais necessidades trabalhistas de mulheres e de homens acostumados com as brenhas da floresta. O domínio da leitura e da escrita, assim, era um privilégio de poucas famílias abastadas.

A partir da década de 1960, a Amazônia começa a sofrer um processo desordenado de urbanização (PRATES; BACHA, 2011) que irá reverberar no âmbito educativo.

As mudanças educativas, segundo Loureiro (2007) se desenham a partir do momento em que, em decorrência da grande migração de pessoas do campo para as cidades, somadas à chegada de mulheres e homens oriundos de outras regiões do Brasil em um processo desenfreado de colonização, estimulados pelos projetos de ocupação e modernização da Amazônia do regime militar, afigura-se um grande inchaço populacional, sobretudo nas áreas urbanas.

Por esse ângulo, as pessoas que chegavam às grandes capitais, necessitavam da escolarização para exercerem profissões próprias da vida urbana. Bosqueja-se, deste modo, o entrelaçamento da ausência de escolarização com as altas estatísticas de miséria e pobreza.

A situação se agravou na década de 1970, com as reformas educativas propostas para o período:

A lei de diretrizes e bases-LDB de 1971, reformula a educação básica encurtando a permanência do aluno na escola. Funde o ensino primário e o ginásio, criando o ensino de $1^{\circ}$ grau, com 8 anos. Da soma resultou a diminuição de 10 anos para 8 anos obrigatórios (LOUREIRO, 2007, p.23).

Ainda para a geógrafa, as consequências da LDB, sobretudo em regiões como a Amazônia, seriam catastróficas no sentido de que, o ensino público, ao perder dois anos, equivalentes à pré-escola, ofertaria uma estrutura educacional deficitária para as 
camadas subalternas, que não possuem condições financeiras para se manterem em escolas particulares que ainda disponibilizavam os 10 anos de ensino.

Além disso, a ausência de uma infraestrutura digna agride a qualidade do ensino nas escolas públicas, especialmente as escolas multisseriadas ${ }^{4}$. Hage (2005, p.47-8) elenca alguns desses entraves que perduram até hoje, tais como "a precariedade da estrutura física das escolas; as dificuldades dos [as] os professores [as] e estudantes [...] às longas distâncias percorridas e a oferta irregular da merenda" aumentando as discrepâncias educativas amazônicas com relação a outras regiões do Brasil. Nesse sentido reafirma-se o que diz Loureiro (2007) de que as crianças submetidas a um processo de escolarização mutilado pela lógica da modernização, certamente serão adultos com grandes dificuldades de leitura e de escrita.

Na década de 1990, é aprovada a nova Lei de Diretrizes e Bases da Educação Nacional-LDBEN -9.394 de 20 de dezembro de 1996. No corpo de sua redação, de acordo com Souza (2013), chama a atenção a preocupação em projetar uma educação básica capaz de desenvolver o exercício de cidadania do (a) educando (a), possibilitando que o mesmo esteja preparado para o trabalho e para uma educação posterior.

Porém, para esse geógrafo, existem controvérsias:

Há certa dificuldade em alcançar o proposto pela estruturação conservadora da escola. É preciso discutir e planejar as mudanças necessárias para que se alcancem os objetivos pretendidos de uma escola mais cidadã, trabalhando uma formação mais completa dentro da diversidade e complexidade da realidade amazônica brasileira com a participação de todos os sujeitos envolvidos no processo educativo (SOUZA, 2013, p.118-19).

Os pontos levantados pelo intelectual são cruciais, para que não tenhamos uma visão romantizada sobre a LDBEN. Apesar de alguns aspectos positivos, por ela contemplados, como a exigência de que educadoras e educadores ingressassem no curso superior e de que a Educação básica seja também uma responsabilidade dos municípios (LOUREIRO, 2007), os obstáculos ainda são consideráveis no caminho a uma educação de qualidade.

Araújo (2014) em pesquisa realizada com professoras da região de ilhas de Belém, entre os anos de 2009-2011, mais de uma década após a aprovação da LDBEN, constata que $71 \%$ delas possuem apenas o ensino médio e $29 \%$ formação em nível superior.

\footnotetext{
4 Organização do ensino em escolas, geralmente localizadas em áreas de difícil acesso, em que o professor trabalha, na mesma sala de aula, com várias séries simultaneamente.
} 
Dentre essas últimas, destaca-se o fato de que tal formação foi viabilizada por meio de instituições privadas de ensino.

A autora relata que as professoras atribuem as dificuldades para se escolarizar "à escassez de barcos, livros e apoio da família; falta de escolas e de dinheiro; moradia na casa de parentes e/ou conhecidos, falta de energia elétrica, e ter que cedo trabalhar para se sustentar" (ARAÚJO, 2014, p. 4).

Nessa pesquisa, Araújo também constata que a maior parte das professoras não almejavam essa profissão, mas encontraram na docência uma forma de melhorar a renda familiar e ganhar dignidade moral. Isto porque, salienta a autora, as mulheres na Amazônia, desde a colonização, foram tratadas como objetos sexuais à disposição dos homens, a exceção da relação entre índios e índias.

Dessa forma, Araújo (2014, p.13-14) reforça que,

A profissão docente se transforma, no caso dessas professoras, em uma alternativa, ainda que precária, de ultrapassar a linha da exclusão, da exploração e da própria colonização, já que seus corpos continuam sendo usados como há muito. Para estas mulheres, ascender à condição de docentes significa, antes de tudo, proteger-se da violência sexual da infância e da vida adulta. Afinal, quem vai ter coragem de "mexer" com a professora? Para estas professoras a docência promoveu, portanto, não apenas uma ascensão econômica, mas, e principalmente, uma ascensão moral.

Nesse sentido, encontrar uma forma de superar esses entraves é o grande desafio. Pensar e construir uma educação que se descentralize dos conteúdos escolares e que englobe as vivências dos (as) educadores (as) e educandos (as), para além da mera preocupação com o desenvolvimento cognitivo, mas para a formação de um ser ominilateral.

É nesse sentido que buscamos nos escritos de Bell Hooks e Paulo Freire uma reflexão acerca do importante papel exercido pelo corpo e pelas vivências cotidianas da realidade dessas mulheres ribeirinhas da Amazônia paraense no processo educativo, tanto da docência quanto da própria vida.

\section{HOOKS E FREIRE: EDUCADORES INSURGENTES E COMPROMETIDOS COM A LIBERTAÇÃO}

Hooks é uma intelectual à frente do seu tempo. Um misto de sensibilidade epistemológica e engajamento político, sobretudo em aspectos de gênero e de raça, que tornam a sua escrita visceral. 
Aliás, o ato de escrever é uma de suas maiores paixões. Um encanto que a acompanha desde a infância, quando frequentou escolas para negros nos Estados Unidos, em um momento histórico em que a segregação racial imperava.

Uma mulher negra que, ao testemunhar as múltiplas opressões incrustadas nos guetos norte-americanos, encontra na escola um bálsamo de resistência. "O lecionar-oeducar-era fundamentalmente político, pois tinha raízes na luta antirracista" (HOOKS, 2013, p.10). Nesse cenário foi que ela vivenciou um encontro com a pedagogia da revolução. Uma pedagogia costurada pelas mãos de professoras negras que conscientizavam as alunas e os alunos de que a educação era um importante manancial na luta contra a colonização imposta pelos brancos. Segundo a própria feminista negra, suas ações pedagógicas nutriam a responsabilidade de conhecer a realidade das educandas e dos educandos desde suas rotinas até a igreja que frequentavam.

No entanto, a intelectual aponta que com o fim do apartheid e consequentemente, com o término das escolas para negros, os novos ambientes escolares deixaram de ser lugares de prazer, de liberdade e de respeito.

As alunas e os alunos negros eram submetidos a sistemáticos episódios de racismo perpetrados inclusive por professoras e professores brancos. $\mathrm{O}$ ato político, que até então era marcado pela conscientização, na visão de Hooks, passa a resumir-se em resistir a essas violências raciais.

Ao ingressar na Universidade, sua realidade não foi diferente. Embora sustentasse o desejo de ser uma intelectual negra insurgente, o espaço universitário passava mensagens de que mulheres, sobretudo negras, não poderiam alcançar a suposta onipotência epistemológica dos brancos.

É nesse momento que Hooks (2013, p.15) tem o seu primeiro contato com os escritos de Paulo Freire:

Quando descobri a obra do pensador brasileiro Paulo Freire, meu primeiro contato com a pedagogia crítica, encontrei nele um mentor e um guia, alguém que entendia que o aprendizado poderia ser libertador. Com os ensinamentos dele e minha crescente compreensão de como a educação que eu recebera nas escolas exclusivamente negras do sul havia me fortalecido, comecei a desenvolver um modelo para a minha prática pedagógica, já profundamente engajada no pensamento feminista.

O que chama a atenção na ótica da intelectual sobre o pensamento freireano é o verniz de ética que ela procura empregar nesse encontro epistemológico. Uma confluência de ideias avessa ao temor de que possíveis críticas possam brotar desta 
matiz, no sentido de que uma educação transgressora não possui o receio de se reinventar.

Para além disso, Hooks (1981) é ciente de que o feminismo norte-americano ao qual foi apresentada, não estava preocupado em ouvir a sua voz enquanto uma mulher negra. Tratava-se de uma inquietação que se maturava à medida que ela entrava em contato com as leituras freireanas.

Porém, a intelectual não era ingênua com relação às questões sexistas que emergiam das primeiras obras de Freire:

Enquanto lia Freire, em nenhum momento deixei de estar consciente não só do sexismo da linguagem como também do modo como ele (e outros líderes políticos, intelectuais e pensadores críticos do terceiro mundo como Fannon, Memmi etc.) constrói um paradigma falocêntrico da libertaçãoonde a liberdade e a experiência da masculinidade patriarcal estão ligadas como se fossem a mesma coisa. Isso [...] representa um ponto cego na visão de homens que têm uma percepção profunda. Por outro lado, não quero [...] que a crítica desse ponto cego eclipse a capacidade de qualquer pessoa de aprender com as percepções (HOOKS, 2013, p.70).

O que é interessante no posicionamento da intelectual feminista a respeito da linguagem sexista presente nos primeiros livros freireanos é a forma equilibrada de sua interpretação, ao compreender que é difícil se libertar de uma linguagem machista em uma sociedade ocidental que cultiva uma lógica binária de gênero.

Ainda para a intelectual, o caráter pedagógico crítico que perpassa por toda a bibliografia de Freire permite ao mesmo repensar sobre essas e outras possíveis contrariedades que emergem no decurso de seu dinâmico pensamento.

No geral, entende-se que no ponto de vista de Hooks (1981), as obras freireanas saciaram a sua sede ao alcançarem questões raciais, colonizadoras e de classe que a literatura feminista branca e norte-americana procurou ignorar na sua militância e produção acadêmica.

Nessa direção, Mota Neto (2016), afirma que Paulo Freire é um educador do terceiro mundo. Longe de ser um rótulo, essa característica exprime a coerência entre as palavras e as ações protagonizadas por este pedagogo durante toda a sua jornada intelectual e militante.

As mãos freireanas teceram a pedagogia dos (as) subalternos (as) em comunhão, em respeito e com humildade. Demonstrando ser o dono de um corpo que não apenas pensa; sente também. Ao epidermizar as lutas e as resistências das pessoas em situação de opressão, Mota-Neto (2016, p. 150) afirma que: 
A biografia de Paulo Freire o conduziu a pensar a pedagogia a partir dos subalternos; que o oprimido não é o sujeito para quem fala Paulo Freire, mas com quem fala; que ele mesmo, nas lutas político-educacionais que vivenciou no Brasil, em outros países da América Latina, nos Estados Unidos, na Europa, na África, ocupou discursiva e geopoliticamente o lugar do oprimido.

Para o pesquisador, as caminhadas marcantes de Paulo Freire em continentes como a África, reforçaram a sua identidade latina pedagogicamente comprometida com as mulheres e os homens condenados da terra em uma notável luta contra práticas educativas colonizadoras. Dispostas, deste modo, a desvelar a realidade complexa das classes populares.

O pensamento freireano, então, é marcado por sua dinamicidade:

[...]Freire inicialmente abebera-se do existencialismo francês, tão importante para a geração 1950 e 1960 no Brasil. A leitura de Freire do existencialismo, depois ampliada com Karl Jaspers, Jean Paul Sartre, Simone de Beauvoir, Martin Buber e outros, Ihe leva a destacar a responsabilidade do sujeito pela história, o papel ativo das pessoas na construção da sociedade e o ser humano como um ser de busca e relações (MOTA-NETO, 2016, p.153).

$\mathrm{Na}$ visão do pesquisador, são indícios de que Paulo Freire é um intelectual autônomo preocupado em consultar as suas fontes de maneira crítica e, acima de tudo, conectada ao contexto histórico.

Ao nos concentrarmos sobre o reconhecimento do pensamento freireano a respeito do papel ativo das pessoas na construção da sociedade, bem como a responsabilidade humana pela história, visitamos os escritos de Arroyo (2003) que nos apresenta importantes instrumentos a fim de compreendermos as matrizes pedagógicas do pensamento de Paulo Freire.

Nessa lógica, os sujeitos são pensados em movimento, no seio de efervescentes atos coletivos e com múltiplas identidades. Sejam trabalhadores, negros, mulheres, povos indígenas, dentre outros, que ajudam a repensar novas bases educativas a partir de suas pedagogias das resistências.

Arroyo (2003, p.34) contextualiza historicamente o protagonismo dessas esferas sociais marginalizadas, ao estabelecer um paralelo com o advento da Educação Popular freireana:

Paulo Freire construiu sua reflexão e prática educativa, referida sempre aos movimentos de jovens, de trabalhadores, de camponeses, dos anos 1960-70, aos movimentos culturais e de libertação dos povos da África e da América Latina [...] Paulo não inventa metodologias para educar os adultos [as] e camponeses [as] ou trabalhadores [as] nem os oprimidos [as] ou excluídos [as], mas nos reeduca na sensibilidade pedagógica para captar os oprimidos e excluídos como sujeitos de educação, de construção de saberes, conhecimentos, valores e cultura. Sujeitos sociais, culturais, pedagógicos em aprendizados, em formação. 
Uma sensibilidade pedagógica que o pesquisador traduz como a revitalização dos processos educativos, a partir do momento em que os mesmos se encontram dispostos a aprender com as mulheres e os homens em condição de opressão.

\section{POR UMA EDUCAÇÃO FEMINISTA: DIÁLOGOS ENTRE PAULO FREIRE E BELL HOOKS}

Hooks (2013) apresenta pistas que provam as convergências entre uma proposta de pedagogia feminista e o pensamento de Paulo Freire. Nesse sentido, ao analisar as suas experiências educativas ela afirma que preceitos freireanos estavam entrelaçados às práticas pedagógicas de suas professoras negras que estimulavam o exercício crítico nas jovens educandas, como forma de se protegerem do racismo e do sexismo.

Uma pedagogia freireana que privilegia "o reconhecimento da subjetividade dos menos privilegiados, dos que têm de carregar a maior parte dos pesos das forças opressoras" (HOOKS, 2013, p.75). Uma sensibilidade pedagógica que inspirou a mesma a atentar para as pedagogias arquitetadas a partir das próprias opressões vivenciadas pelas mulheres negras.

Uma forma de se contrapor a uma lógica metafísica, marcada pela separação corpo e mente. Uma inteligibilidade, para Hooks (2000), pedagógica masculina, cartesiana e acrescentamos eurocêntrica, que invade os processos educativos e asfixia a expressão dos corpos de mulheres e homens que fazem parte de práticas de ensino e de aprendizagem.

$\mathrm{Na}$ arqueologia das memórias desta feminista e ativista social, nos deparamos com uma mulher, na condição de educanda, enfrentando as repressões de seu próprio corpo na sala de aula, ao frequentar as mesmas escolas que os brancos com o fim do apartheid nos Estados Unidos. Nesse cenário abstrato, a corporeidade de suas professoras e de seus professores não passa, em sua ótica, de uma lembrança desbotada pela proibição oriunda de um pudor acadêmico.

Consequentemente, desejos, sinestesias e prazeres também eram repelidos desses ambientes escolarizados. Um sistema de coibição pedagógico que se capilarizava para a curiosidade e era, paradoxalmente, uma chave para a descoberta de literaturas marginalizadas pelos livros didáticos (SANTOS, 2005).

Em meio a essas bibliografias limítrofes, chamou a atenção de Hooks (2000, p. 83), um artigo publicado em uma revista de psicologia que descreve uma pesquisa sobre a revelação de que "a cada segundo, durante suas aulas, muitos professores homens 
estavam pensando sobre sexualidade-estavam, até mesmo, tendo pensamentos libidinosos sobre as estudantes." Uma leitura que despertou na educadora norteamericana muitas inquietações.

Entendemos que na visão da intelectual, tal descoberta engendrou sentimentos confusos, especificamente, com referência à sua carreira docente bem como a sua relação com suas alunas e seus alunos. Dilemas bosquejados pela indecisão entre ser uma educadora apática, ou uma professora disposta a estabelecer laços afetivos com as suas turmas.

Hooks (2000, p.83) descreve um interessante episódio fruto desse impasse:

Havia um estudante em minha aula que eu sempre parecia ver e não ver ao mesmo tempo. Quando chegou a metade do semestre, recebi uma chamada da terapeuta da escola que desejava falar comigo sobre o modo como eu tratava este estudante na sala de aula. A terapeuta contou-me que os estudantes tinham dito que eu era [...] brusca, rude e indubitavelmente dura quando eu me relacionava com ele. Eu não sabia exatamente quem era o estudante, não era capaz de ligar um corpo ou um rosto ao seu nome, mas, depois, quando ele se identificou em aula, me dei conta de que eu estava eroticamente atraída por este estudante.

A sua narrativa exprime a angústia de uma educadora que não sabe como lidar com a sua corporeidade em uma sala de aula ao perceber que, para além de mentes, as carteiras estão ocupadas com corpos que pulsam, que dançam e se expressam sedentos por estabelecerem laços pedagógicos afetivos.

Atraída pelo estorvo que esse acontecimento originou, a feminista mergulha, novamente, em leituras periféricas que the mostraram um aspecto impregnado no imaginário científico: os homens intelectuais incontestavelmente respeitados, pensam com os seus corpos. Diferentemente, as mulheres necessitam, primeiramente, provar que são pensadoras e isso implica em uma cruel abstração ilustrada pelo modelo do homem universal (HOOKS, 2000).

Salles (1956 apud SIMONIAN, p.5) comenta que na Amazônia, "a vovó e a titia caboclas são enciclopédias vivas [...] mas apesar de sua importância no que diz respeito à transmissão de conhecimentos, seus nomes ficaram no passado" pelo fato de estarem exiladas de um padrão epistemológico, metafísico, branco e androcêntrico.

A separação corpo e mente é a responsável por tornar o processo educativo apático. No entanto, a resistência se vislumbra quando as mulheres, em suas atividades intelectuais e docentes, abraçam um pensamento crítico e não descorporificado (HOOKS, 1981). 
Nesse contexto, reflete-se sobre "a conscientização crítica [que] está enraizada na suposição de que conhecimento e o pensamento crítico dados na sala de aula deveriam orientar nossos hábitos de ser e modos de vida fora da sala de aula" (HOOKS, 2000, p.84). É fundamental destacar que suas elucubrações florescem no seio de uma disciplina da qual ela ministrou denominada de "estudos de mulheres" em que ela ressalta a relevância de uma educação feminista.

Na visão de Freire e Macedo (1998, p.208) "a prática pedagógica correta para as feministas é compreender os diferentes níveis de opressão masculina" de maneira a possibilitar pedagogicamente que os homens confrontem essas formas de opressões.

Oliveira (2015, p.220) aponta a influência freireana para a edificação do pensamento da ativista norte americana:

Hooks mostra como a obra de Paulo Freire permitiu-lhe compreender as limitações do ato pedagógico que ela mesma havia tido como aluna e, ao mesmo tempo, como inspirou-se em professoras (es) que a auxiliaram a transgredir fronteiras incentivando-a a dar um passo além das aprendizagens que mais se parecem com a rotina de uma linha de produção.

Acreditamos que o pensamento filosófico e educativo de Paulo Freire nos aponta caminhos para pensarmos em novos paradigmas educativos que despertem nos (as) educadores (as) a auto realização ao mesmo tempo em que se sensibilizam com as motivações íntimas dos (as) educandos (as) para uma pedagogia feminista.

Interpretamos os alicerces de um feminismo educativo como importantes raízes ontológicas de relações amorosas, respeitosas, dialógicas e éticas no decurso de uma inteligibilidade corporificada e não abstrata e que, por isso, espraia-se para a realidade das próprias educandas e dos educandos.

O território amazônico, nesse aspecto, urge por uma prática educativa que se sensibilize com as biografias de suas mulheres. As quais, enfrentam "processos de negação de suas identidades e anulação de sua importância diante da lógica instrumental e produtivista que as enclausura em uma condição de opressiva" (SILVA, 2011, p.11) sobretudo, acrescenta-se, no âmbito educativo.

É necessário, destarte, combater práticas educativas extremamente retóricas, abstratas e opressivas. Um contexto educativo marcado por ser "algo parado, estático, compartimentado e bem comportado quando não falar [...] sobre algo completamente alheio à experiência existencial dos (as) educandos (as) vem sendo, realmente, a suprema inquietação desta educação" (FREIRE, 1987, p.33). Contexto em que apenas o (a) educador (a) é agente do processo educativo. 
Necessita-se atentar para os processos de humanização e desumanização, existentes na complexa realidade social, e que podem enraizar ou desenraizar as mulheres e os homens da órbita de suas decisões (FREIRE, 1967).

Para Arroyo (2010), não há dúvidas de que a visão freireana sobre as camadas subalternas é radicalmente humana. Em sua obra "Pedagogia do oprimido," o intelectual pernambucano tece uma provocação com referência ao sujeito enquanto uma problematização na esfera pedagógica.

$\mathrm{Na}$ visão de Apple (2013), O pensamento freireano alimenta importantes movimentos educacionais e políticos contrários a uma cultura hegemônica. Freire teceu teorias vivas e dinâmicas atentas às modificações históricas e geográficas de múltiplas localidades em que dialogou.

Trata-se, para o intelectual norte-americano, de uma pedagogia intensa e resistente que atenta para a necessidade de estabelecer a cadência entre a raça, a classe e o gênero. Uma educação freireana embasada na mestiçagem entre o intelecto e a emoção:

Seus impulsos originais em relação ao trabalho teórico-educativo e político foram alimentados por uma paixão pela justiça social, a igualdade econômica, os direitos humanos, o meio ambiente sustentável, uma educação que seja digna do nome, resumindo, um mundo melhor [grifo nosso] (APPLE, 2013, p.51-2).

Para Saul (2016, p.13), a justiça social é um notável elemento no âmbito do pensamento freireano. Ao falar sobre Freire, ela aponta que sua vida e obra "revelam a sua indignação contra as injustiças sociais que negam a humanização. Desde seus primeiros escritos, esse tema esteve presente. Engendrando a utopia de sua proposta pedagógica e política." Nessa direção, aspectos desumanizantes como a cultura do silêncio foram exaustivamente debatidos nos livros de Paulo Freire.

A cultura do silêncio é uma categoria freireana chave para que possamos compreender a lógica da opressão. "Ser silencioso não é ter uma palavra autêntica, mas seguir as prescrições daqueles que falam e impõe sua voz" (FREIRE, 1979, p.33). Ou seja, as camadas subalternas absorvem os discursos das esferas sociais dominantes.

Nesse rumo, para o educador, se desenha a teoria da dependência, na qual o centro das decisões se situa no exterior do contexto social que alicerça a situação de fragilidade das nações subdesenvolvidas.

Ao ponderar uma forma de subverter a inteligibilidade da dependência, Freire (1979), propõe os desafios de se pensar a partir do seio de uma determinada sociedade e 
o reconhecimento de que as camadas populares apresentam raciocínios caros a sua sobrevivência e que não podem ser menosprezados pelo conhecimento científico.

O pensamento freireano lança o desafio de edificar uma educação a partir da realidade concreta:

A gente precisa molhar o corpo da gente nas mesmas águas culturais do oprimido [...] uma escola que seja vivida ou cujo os conteúdos programáticos correspondam à ansiedade dos [as] educandos [as], e historicamente, culturalmente, socialmente, uma escola em que os [as] educandos [as] exercitem o direito de ser sujeitos (FREIRE, 2005, p.33-4).

Oliveira (2016) indica uma educação freireana disposta a fazer uma interpretação crítica do mundo que desvele os discursos ideológicos dominantes. Nesse contexto, o [a] educando [a] é visto [a] como produtor de conhecimento e cultura, permeado por uma leitura de mundo ética, política e existencial.

Ainda para a intelectual, na raiz da trama social vivenciada pelos (as) educandos (as) bosqueja-se uma identidade cultural que se interliga a outros conhecimentos por meio de uma pedagogia dialógica.

Freire (1983, p.36) indica que "o diálogo e a problematização não adormecem a ninguém, conscientizam [...] uma postura crítica da qual resulta a percepção de que este conjunto de saber permanece em interação." A promoção da interação entre diferentes conhecimentos não seria possível, por outro lado, sem a tolerância.

O exercício de tolerância é crucial para uma pedagogia plural. É fundamental respeitar as diferenças sem cair na armadilha de estabelecer comparações estéreis por meio de uma interpretação crítica do diferente a fim de não estabelecer juízos de valores negativos. Nesse ensejo, podemos cultivar as nossas opiniões, porém, respeitando pontos de vista distintos (FREIRE, FAUNDEZ, 1985).

É nesse sentido que Freire advoga a favor do amor pela vida. Na perspectiva de uma concepção biofílica de existência, que contrasta com uma compreensão necrófila em que tudo está sob o domínio da opressão. "A terra, os bens, a produção, a criação dos [as] homens [mulheres] [...] tudo se reduz ao objeto de seu comando" (FREIRE, 1987, p.25). Provoca a ruptura da existência humana com o mundo em que faz parte.

A leitura biofílica da existência humana nos leva, também, a compreender a força motivadora que leva mulheres e homens a experimentarem a cognoscibilidade.

Segundo Freire (1967, p.39):

Há uma pluralidade nas relações do [a] homem [mulher] com o mundo, na medida em que responde à ampla variedade dos seus desafios. Em que não se esgota em um tipo padronizado de resposta. A sua pluralidade não é só em face dos diferentes desafios que partem do seu contexto, mas em 
face do mesmo desafio. No jogo constante de suas respostas, altera-se no próprio ato de responder [...] Ademais, é o [a] homem [mulher], e somente ele [a] capaz de transcender [...] na raiz de sua finitude. $\mathrm{Na}$ consciência que tem desta finitude.

Freire (1967) indica caminhos que não devem ser menosprezados pelos processos pedagógicos para que o desejo pelo conhecimento seja despertado nas educandas e nos educandos. Há um verniz existencialista em seu pensamento que considera a existência humana como um eterno vir a ser.

$\mathrm{Na}$ visão do intelectual, essa é a chave para que possamos compreender a importância de relações horizontais entre educadores (as) e educandos (as). Ao se direcionar às camadas subalternas, Freire e Nogueira (1999, p.22) percebem que "a luta engendra um saber em certo nível. Sempre que se luta e peleja, há uma noção, há uma certa claridade sobre aquilo porque se luta." Há um processo educativo em que a curiosidade ingênua caminha para uma transformação epistemológica.

Assim, através do desejo pelo conhecimento e dos preceitos freireanos, passamos a compreender o Eros e o erótico nas práticas pedagógicas a partir de sentidos plurais que vão para além de uma conotação sexual. Keen (1992 apud Hooks 2000, p.85) aponta que "a potência erótica não está confinada no poder sexual, mas inclui a força motriz que faz com que qualquer forma de vida deixe de ser mera potencialidade para alcançar sua plena realização." Um desejo global que move a própria vida.

Compreendemos que, ao simplificarmos o erotismo a uma conotação sexual, perdemos a oportunidade de perscrutar as forças sinestésicas, corpóreas e cognitivas, embaladas pelo prazer em buscar os conhecimentos que temperam os processos de ensino e aprendizagem por meio das próprias experiências dos (as) educandos (as). Afinal, o ato de educar deve ser uma fonte de prazer (ALVES, 2011).

Para Hooks (2000), um dos motivos de uma interpretação equivocada sobre o erótico no contexto educativo é a visão superficial que a grande maioria das educadoras e dos educadores possuem sobre o conceito de higiologia.

Segundo Montes (2010, p.22) "la higiologia reconoce en esta admirable simpatia que armoniza la sociedade si se dirigi bien [...] la conservacion individual y la de la especie es tambien presidida por este poder invisível." Um processo harmônico que se revela em paixões que nos complementam a partir do bem estar que as mesmas nos proporcionam.

Como esses conceitos de saúde e bem estar desenham-se no contexto educativo? O significado de práxis se torna uma categoria chave para um processo pedagógico 
capaz de transformar a realidade em meio a uma estratégia política e pedagógica (GADOTTI, 1995).

Nesse sentido, a práxis e a paixão pelos processos de ensino e aprendizagem se complementam harmonicamente. Para Gadotti (1995, p.18) a verdadeira pedagogia deve engajar-se "no compromisso com a transformação social. Dialogar não é trocar ideias. $O$ diálogo que não leva à ação transformadora é puro verbalismo." Vislumbramos, assim, a possibilidade de um rompimento com relações hierárquicas entre educadores (as) e educandos (as) a partir da paixão pelos processos de ensino e aprendizagem.

Nessa direção, as complexas lutas, resistências e violações experienciadas pelos (as) oprimidos (as) imiscuem-se na realidade educativa. De maneira a ensejar o casamento entre a teoria e a prática tão caros ao processo de humanização das teorias pedagógicas.

Sobre essa paixão:

$\mathrm{Na}$ medida em que nós, professoras e professores carregamos esta paixão, que tem de estar fundamentalmente enraizada no amor pelas ideias que somos capazes de inspirar, a sala de aula se torna um lugar dinâmico no qual transformações nas relações sociais são concretamente realizadas e a falsa dicotomia entre o mundo externo e o mundo interno da academia desaparece (HOOKS, 2000, p.85).

A intelectual complementa que pensar nessa paixão ainda é um desafio para muitas realidades educativas, ou seja, ainda que se discuta sobre processos de amorosidade e diálogo na sala de aula, o afeto, a amizade e o prazer ainda parecem ser temas polêmicos para muitas educadoras e educadores.

O diálogo e a amorosidade são categorias vitais. Mulheres e homens entrelaçamse ao mundo por meio do diálogo. O amor, por sua vez, é uma atitude coletiva que se contrapõe a uma lógica individualista e egoísta e deve se materializar em uma prática docente amorosa, não de um ponto de vista piegas, mas sim, politicamente compromissado (FREIRE, 1992).

Nesse sentido, podemos encontrar exceções no âmbito educativo. Em sua experiência como professora do departamento de estudos afro-americanos de Yale, Hooks (2013) vivenciou de forma magistral o entrelaçamento, por meio da filosofia da educação, entre a literatura e a pedagogia.

Nessa direção, "o ser humano é intelectual, é filósofo porque participa de uma concepção de mundo. Essa filosofia no olhar de Gramsci [...] estaria contida na própria linguagem, no senso comum, no bom senso e na religião popular" (OLIVEIRA, 2015, 
p.47). Por meio da coletividade e da cultura, o pensamento humano se cria e se transforma.

Ainda para a intelectual, Freire, ao incorporar essa interpretação filosófica, reconhece que o cotidiano dos grupos subalternos é cenário de lutas e resistência. Por isso, as práticas educativas necessitam estar impregnadas de sentidos políticos. É urgente um esforço ininterrupto em questionar as matrizes capitalistas e neoliberais que asfixiam as autonomias das mulheres e dos homens subalternizados (FREIRE, 2001) sobretudo em territórios como a Amazônia.

Dessa forma, temáticas como racismo, sexismo, colonialismo e violência doméstica devem ser problematizadas na sala de aula, juntamente com os conteúdos escolares, de maneira a edificar uma pedagogia feminista através de um olhar filosófico.

A promoção de processos pedagógicos significativos e prazerosas capazes de irem ao encontro, no contexto educativo amazônico, de "uma reflexão acerca do papel atribuído às mulheres na história da Pan-Amazônia, e como esse papel se distancia daquilo que elas são e sentem em suas existências e vivências particulares" (SILVA, 2011, p.13). Apresenta-se, assim, o Eros enquanto uma experiência amorosa, ética e política na sala de aula.

Exemplos de que é possível divorciar-se de uma falsa neutralidade científica que impede a amorosidade no exercício da prática docente:

[...] temor de que a presença de sentimentos, de paixão, possa impedir uma consideração objetiva do mérito de cada estudante. Mas essa concepção está baseada na falsa pressuposição de que a educação é neutra, de que há uma base emocional sobre a qual podemos nos apoiar de modo a tratar todos igualmente, desapaixonadamente (HOOKS, 2000, p.87).

As considerações de Hooks (2000) e do pensamento freireano são relevantes para repensarmos a prática pedagógica de maneira inclusiva, crítica e ativa. Especialmente sobre uma sociedade, como a Amazônia, que sofre com as mazelas do capitalismo, contaminadas pela representação da escola enquanto um espaço marcado pela meritocracia, pela competição e por uma idílica ideia de mosteiros e paraísos, onde apenas um seleto grupo de intelectuais homens possuem acesso ao conhecimento.

É nesse sentido, não apenas político, mas também ético, que se estabelece uma educação humanizadora. Freire (1967) explica que humanizar é manter mulheres e homens enraizados, e não acomodados, na órbita de suas decisões. Uma pedagogia feminista deve, assim, promover um movimento coletivo de consciência e libertação. 


\section{CONSIDERAÇÕES FINAIS}

A trajetória histórica da educação na Amazônia é permeada por muitos conflitos. Há um emaranhado de questões sociais, políticas e jurídicas que exigem práticas pedagógicas cada vez mais comprometidas com as mulheres e os homens que ocupam os territórios amazônicos com os seus saberes negados pela lógica eurocêntrica, mas que ainda assim resistem ao mutismo brutalmente imposto em seus corpos.

É no seio dessas resistências que perscrutamos respostas para muitas inquietações. Dentre elas, o desejo de saciar a sede por uma escola que dialogue com a diversidade cultural, ontológica, mística e comunitária dos povos que vivem na Amazônia.

Um contexto escolar orientado por uma educação feminista que não está enclausurada à luta contra a violência sexista, apenas; que também denuncia as constelações de opressões que tingem de vermelho o solo amazônico, ao mesmo tempo em que anuncia novos paradigmas pedagógicos regados pelas vivências, militâncias e escritos de intelectuais insurgentes como Paulo Freire e Bell Hooks.

Dois intelectuais que já sentaram à mesa, e partilharam uma longa conversa. Descobrindo em comum, a preocupação em serem intelectuais que, apesar de se encontrarem no âmbito acadêmico, respeitam os saberes dos subalternos. Além de partilharem de seus conhecimentos e experiências com os oprimidos, costuram uma pedagogia com um sentido de justiça e por isso, indignada com as violências e desumanizações. Por ser alicerçada a partir das práticas dos movimentos sociais, ultrapassa, comumente, os muros da escola encorpando diferentes dinâmicas territoriais e relações humanas.

\section{REFERÊNCIAS}

ALMEIDA, Edwana Nauar de. O corpo escalpelado: possibilidades e desafios docentes no cotidiano de meninas ribeirinhas na Amazônia paraense. 2016, 208 f. Dissertação de mestrado (Programa de pós-graduação em educação) - Universidade Federal do Pará, 2016.

ALVES, Rubem. Variações sobre o prazer. São Paulo: Planeta, 2011.

APPLE, Michael. As tarefas do estudioso/ativista crítico em uma época de crise educacional. Pedagógica. Unochapecó, v.1, n.30, jan/jun.2013.

ARAÚJO, S. M. S. História das mulheres, história de vida de professoras: elementos para pensar a docência. Educar em Revista, Curitiba, Brasil, n. 53, p.295-310, jul. /set. 2014. Editora UFPR. 
ARROYO, Miguel. Pedagogias em movimento-o que temos a aprender dos movimentos sociais? Currículo sem fronteiras, v.3, n.1, p.28-19. Janljun, 2003.

. Políticas educacionais e desigualdades: à procura de novos significados. Educação e sociedade. Campinas, v.31, n.113, p.1381-416. Outldez. 2010.

BRASIL, Ministério da saúde. Tecendo a saúde das mulheres do campo, da floresta e das águas: direitos e participação social. Ministério da saúde. Brasília, 2015.

FREIRE, Paulo. Educação como uma prática de liberdade. Rio de Janeiro: Paz e Terra, 1967.

. Conscientização: teoria e prática da libertação: uma introdução ao pensamento de Paulo Freire. São Paulo: Cortez e Moraes, 1979.

. Extensão ou comunicação? 8.ed. Rio de Janeiro: Paz e Terra, 1983. Terra, 1985.

; FAUNDEZ, Antônio. Por uma pedagogia da pergunta. Rio de Janeiro: Paz e

Pedagogia do oprimido. 17.ed. Rio de Janeiro: Paz e Terra, 1987.

; MACEDO, Donaldo. Um diálogo com Paulo Freire. In: MCLAREN, Peter. Et al. Paulo Freire: poder, desejo e memórias de libertação. Trad. Márcia Moraes. Porto Alegre: Artmed, 1998.

; NOGUEIRA, Adriano. Que fazer teoria e prática em educação popular. 5.ed. Rio de Janeiro: Vozes, 1999

Pedagogia da tolerância. São Paulo: UNESP, 2005.

GADOTTI, Moacir. Pedagogia da práxis. 2.ed. São Paulo: Cortez, 1998.

GÓES, Wany Marcele Costa. Educação popular em ambiente hospitalar. 2009, $190 \mathrm{f}$. Dissertação de mestrado (Programa de pós-graduação em educação) - Universidade do Estado do Pará, 2009.

HAGE, Salomão Mufarrej. Classes multisseriadas: desafios da educação rural no estado do Pará/região amazônica. In: Educação do campo na Amazônia: retratos de realidade das escolas multisseriadas no Pará. Belém: Gutemberg, 2005.

HOOKS, Bell. Eu não sou uma mulher. Mulheres negras e feminismo. 1.ed. São Paulo: Plataforma Gueto, 1981.

Eros, erotismo e o processo pedagógico. In: LOURO, Guacira Lopes (org). 0 corpo educado pedagogias da sexualidade. 2.ed. Tradução de Tomaz Tadeu da Silva. Belo Horizonte: autêntica, 2000.

Ensinando a transgredir: a educação como prática de liberdade. São Paulo: Martinsfontes, 2013 
LOUREIRO, Violeta Refkalefsky. Educação e sociedade na Amazônia em mais de meio século. Cocar, v.1, n.1, janljul. 2007.

; NOGUEIRA, Adriano. Que fazer teoria e prática em educação popular. 5.ed. Rio de Janeiro: Vozes, 1999.

MOTA NETO, João Colares da. Por uma pedagogia decolonial na América Latina reflexões em torno de Paulo Freire e Orlando Fals Borda. Curitiba: CRV, 2016.

OLIVEIRA, Ivanilde Apoluceno de. Paulo Freire gênese da educação intercultural no Brasil. Curitiba: CRV, 2015.

PRATES, Rodolfo Coelho; BACHA, Carlos José Caetano. Os processos de desenvolvimento e desmatamento da Amazônia. Economia e sociedade. Campinas, v.20, n.03, p.601-36, dez. 2011.

SANTOS, Glauce Souza. Intelectuais negras. Estudos feministas. Florianópolis, v.3, n.2, p.464-78, agoldez. 2005.

SAUL, Ana Maria. Paulo Freire na atualidade: legado e reinvenção. E-curriculum. São Paulo, v.14, n.1, p.09/34, jan/mar. 2016.

SILVA, Marilena Loureiro da. Prefácio. In. Mulheres Pan-Amazônidas: enciclopédia cooperativa de biografias. Belém: NAEA, 2011.

SIMONIAN, Ligia Lopes. Mulheres Pan-Amazônidas enciclopédia cooperativa de biografias. Belém: NAEA, 2011.

SOUZA, José Camilo Ramos de. A geografia nas escolas das comunidades ribeirinhas de Parintins: entre o currículo, cotidiano e os saberes tradicionais. 2013. $245 \mathrm{f}$. Tese de doutorado (Programa de pós-graduação em geografia física)-Universidade de São Paulo, 2013.

WOLFF, Cristina Scheibe. Mulheres da floresta: uma história-Acre-Alto Juruá (19901954). São Paulo: Hucitec, 1999. 